Document downloaded from:

http://hdl.handle.net/10251/80742

This paper must be cited as:

Broatch Meza, A.; Galindo, J.; Navarro, R.; R. Navarro; Garcia Tiscar, J. (2016). Numerical and experimental analysis of automotive turbocharger compressor aeroacoustics at different operating conditions. International Journal of Heat and Fluid Flow. 61B:245-255. doi:10.1016/j.ijheatfluidflow.2016.04.003.

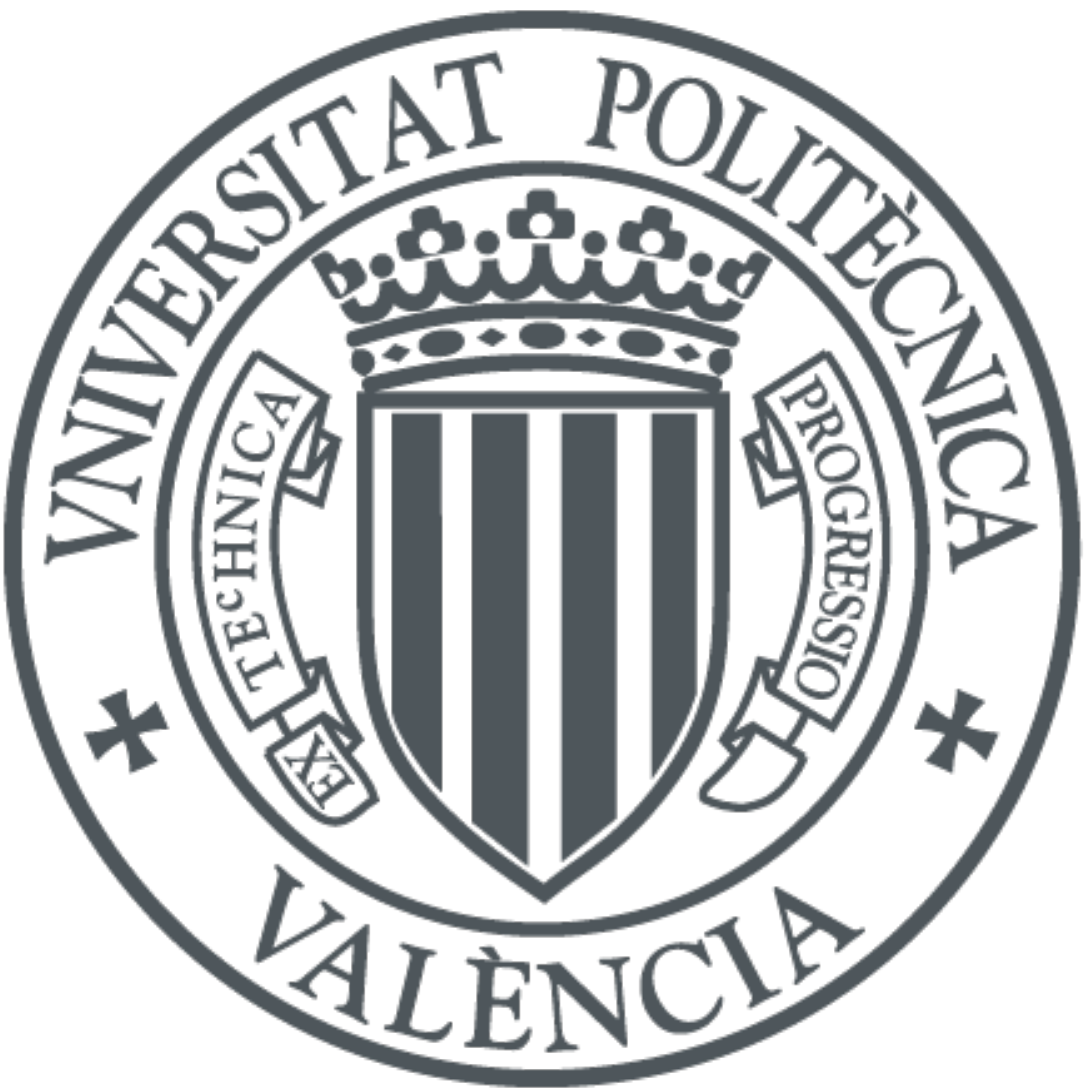

The final publication is available at

http://dx.doi.org/10.1016/j.ijheatfluidflow.2016.04.003

Copyright Elsevier

Additional Information 


\title{
Numerical and experimental analysis of automotive turbocharger compressor aeroacoustics at different operating conditions
}

\author{
A. Broatch, J. Galindo, R. Navarro*, J. García-Tíscar \\ CMT - Motores Térmicos, Universitat Politècnica de València \\ Camino de Vera, 46022 Valencia
}

\begin{abstract}
Centrifugal compressor aeroacoustics are analyzed by means of a 3-dimensional CFD model. Three operating points at nominal compressor speed are simulated ranging from best efficiency point to near-surge conditions. Experimental measurements are obtained using a steady flow rig mounted on an anechoic chamber. URANS and DES predictions of compressor global variables and pressure spectra are compared against experimental measurements. Flow-induced noise increases as the operating point moves towards surge line. Stall at the suction side of the blades exists even for high mass flow conditions, causing a high frequency boundary layer oscillation. Low momentum cells rotating at the diffuser are found at points closer to surge, causing the so-called whoosh noise. Inducer rotating stall is also present at these conditions. Point closest to surge shows a rotating tornado-type vortex at the inducer, determining a moving low pressure region that increases low frequency noise content.
\end{abstract}

Keywords: CFD, Centrifugal compressor, URANS, DES, Rotating stall, Whoosh noise

\section{Introduction and literature review}

Literature survey about the ISO 362 vehicle pass-by noise test conducted by Braun et al. [1] indicated that intake and exhaust systems are regarded as one of the main noise sources by most of researchers.

Particularly, Stoffels and Schroeer [2] showed that radiated noise in low speed range (below $2800 \mathrm{rpm}$ ) of a downsized turbocharged gasoline powertrain is higher than that of an engine with the same power but larger displacement. It is a common belief that development of strongly down-sized engines with increased low speed torque has increased turbocharger compressor airborne noise [3], due to the operating points being closer to surge region [4].

Compressor flow-induced acoustics is becoming a major issue for automotive car makers. It is therefore understandable the increasing number of publications concerning this topic in the last decade, most of which are mainly experimental. Works by Evans and Ward [3], Teng and Homco [4] or Sevginer et al. [5] identified compressor NVH issues by measuring noise radiation. Particularly, a broadband noise denoted as whoosh noise was identified. A common way to reduce noise radiation was the use of resonators in compressor outlet hose.

Nevertheless, if flow phenomena leading to whoosh noise were known, quieter centrifugal compressors could be designed. Most common way of getting some insight of compressor aeroa-

\footnotetext{
*Corresponding author. Tel.: +34963877650

Email addresses: abroatch@mot.upv.es (A. Broatch), galindo@mot.upv.es (J. Galindo), ronagar1@mot.upv.es (R. Navarro), jorgarti@mot.upv.es (J. García-Tíscar)
}

coustics has been the use of wall flush mounted pressure transducers.

Ha et al. [6] measured the internal pressure fluctuation of a centrifugal compressor at different operating conditions at three stages: before the leading edge, after the trailing edge and after the diffuser. Moreover, external microphones were also used. SPL at impeller inlet presented a sudden increase when moving from best efficiency point (BEP) to stall conditions, due to onset of flow detachments and backflows. Impeller and diffuser outlet spectra are alike: they show a broadband increase in 2-4 $\mathrm{kHz}$ frequency range when reducing mass flow from BEP. At stall conditions, a tone appears at $90 \%$ of rotation order, being attributed to rotating stall. Oriffice noise measured with external microphones is consistent with compressor inner probes spectra: amplitude in low frequency range is increased as mass flow is reduced.

Other experimental studies such as the ones carried out by Mongeau et al. [7] or Raitor and Neise [8] are also based on a detailed instrumentation with pressure transducers. This approach is quite challenging for passenger car turbocharger compressors due to their small size. In the last years, though, researchers are able to investigate centrifugal turbomachinery aeroacoustics using CFD because of the increase of computational capabilities.

Liśkiewicz et al. [9] performed an experimental investigation of centrifugal blower acoustic signature in which pressure spectral maps were obtained at different probe locations for different operating conditions. Subsynchronous narrow band disturbances were found even at stable points. Before onset of surge-related noise, the acoustic signature notably changes at the maximum compression ratio point. This change was at- 
tributed to inlet recirculation.

Jyothishkumar et al. [10] analyzed the unsteady flow of a ported shroud centrifugal compressor at design and near-surge conditions using LES. Frequency decomposition of tangential velocity traces obtained at several diffuser probes was performed. A tone at $50 \%$ of rotational speed was observed at the operating point with less mass flow rate, indicating the existence of rotating stall at near-surge conditions.

Bousquet et al. [11] conducted a numerical study of a centrifugal compressor. Three operating points were studied from peak efficiency to near stall conditions. A virtual probe linked to the relative frame located at $90 \%$ span at the impeller inlet was used for pressure spectral analysis. Stator vane passing frequency tone is the main feature for the two operating conditions with higher mass flow. Near stall, lower frequency content appears, particularly a tone at a frequency 6 times the rotation order. Frequency content below rotation order was not investigated.

Mendonça et al. [12] investigated turbocharger compressor aeroacoustics by means of CFD. SPL spectra revealed a narrow band noise at a frequency about $70 \%$ of rotational speed. Leading-edge detachment and stalled passages were found. Rotating stall was detected in the form of a low momentum region that rotates at a slower speed than the impeller, being regarded as the source of the narrow band noise. The authors considered that tip leakage pushed the low momentum region to the adjacent passage thus allowing the stalled passages to recover.

Fontanesi et al. [13] performed detached eddy simulations of a turbocharger compressor with a compressor by-pass valve (CBV). Two operating points at the same isospeed were investigated: one close to surge and the other at a two times higher mass flow rate. At low frequency range (below $5 \mathrm{kHz}$ ), simulation with higher mass flow provides a lower overall noise than the point close to surge. A narrow band noise at $2500 \mathrm{~Hz}$ stands out in both spectra, wich is attributed to periodic flow detachment and re-attachment at the CBV junction. Experimental measurements also detect the aforementioned narrow band.

The literature review proves that CFD is useful to investigate turbocharger compressor flow-induced acoustics, because it could be used to find an explanation for pressure spectra features, such as whoosh noise. In this paper, simulations of three centrifugal compressor operating points at same speed are studied, comparing URANS and DES turbulence models against experimental measurements.

The paper is organized as follows. Section 2 describes the CFD model used in this paper. Comparison of URANS and DES global variables and acoustic spectra against experiments is performed in Section 3 Section 4 is devoted to the investigation of the flow field in order to identify the phenomena responsible for the acoustic signature features. Finally, paper conclusions are provided in Section 5 .

\section{Numerical model}

A CFD model of a turbocharger compressor was developed using Star-CCM+ [14]. The impeller with 6 full and 6 splitter blades was digitalized along with the vaneless diffuser and

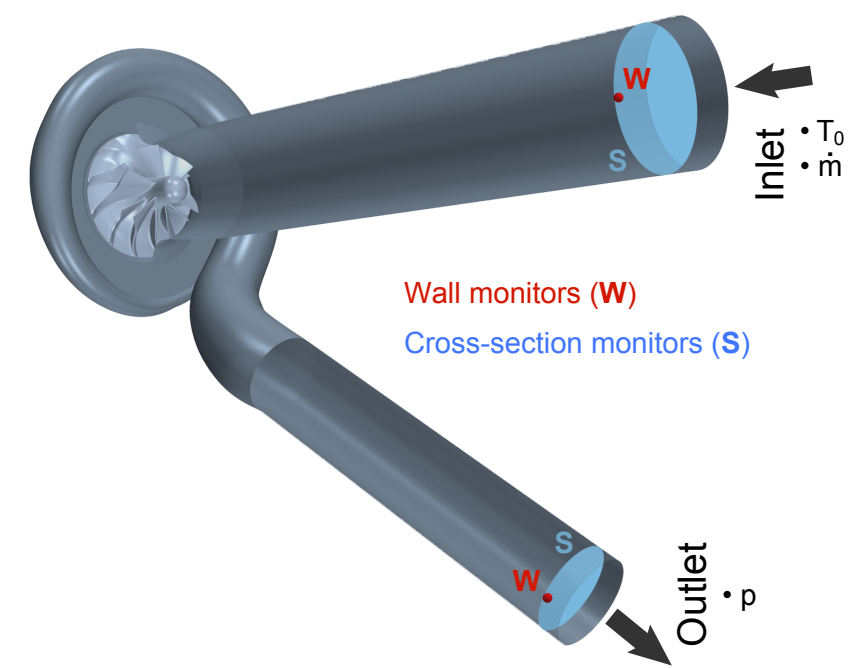

Figure 1: CFD domain including monitor types and locations and flow variables imposed at the boundary conditions.

compressor volute. The domain depicted in Fig. 1 is completed with the extrusion of 5-diameters-long inlet and outlet ducts. The overall mesh consists of 9.5 million polyhedral cells. Backplate clearance along with tip gap are considered in the model, as can be seen in Fig. 2 CAD clearance is considered instead of actual tip gap existing when compressor is running because Galindo et al. [15] found that centrifugal compressor noise production in near surge conditions is not sensitive to tip clearance ratio.

Transient simulations with a segregated, second-order time accurate solver were performed with a time-step size so that the impeller mesh turns $1^{\circ}$ per time step, which was selected in accordance with the sensitivity analysis conducted by Navarro [16].

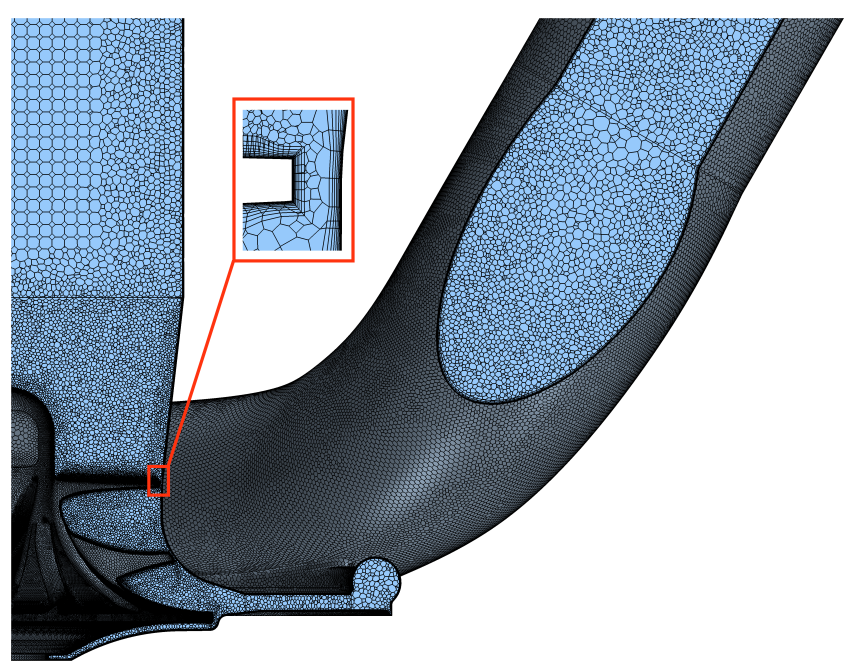

Figure 2: Slice of computational grid, showing a close-up of tip clearance and the boundary layer mesh inflation. Inlet and outlet ducts present the displayed grid pattern until their respective boundary. 
Impeller rotation was considered using the rigid body motion approach.

Fixed outlet pressure and inlet mass flow rate boundary conditions were used, as indicated in Fig. 1. Broatch et al. [17] proved that NRBCs are not mandatory to predict the compressor acoustic signature provided that a pressure decomposition algorithm is used (further information is provided in Section 3.3. 3 operating conditions at $1.4,1.8$ and 2.5 times surge mass flow at a constant compressor speed close to $160 \mathrm{krpm}$ were simulated. According to Serrano et al. [18], compressor heat transfer with the surroundings at this compressor speed is of little importance, being thus neglected in the present paper.

Calculations of these operating conditions were performed with URANS and DES turbulence models. In this work, URANS simulations are performed with $k-\omega$ SST turbulence closure model [19]. This model is very suited for compressors, for its accuracy in predicting flow with adverse pressure gradients [20, 21]. For the sake of comparison, DES also employs the $k-\omega$ SST turbulence model, "which functions as a sub-gridscale model in regions where the grid density is fine enough for a large-eddy simulation, and as a Reynolds-averaged model in regions where it is not" [22]. Particularly, IDDES variant of DES is used [23], in which WMLES and DDES hybrid RANSLES approaches are blended. URANS and detached-eddy simulations use the same 9.5 million cells mesh depicted in Fig. 2 , since the mesh independence analysis performed by Navarro [16] showed that both turbulence models require at least this fine grid to provide consistent predictions. Section 3 will include a comparison of global compressor variables and noise predictions depending on turbulence approach.

\section{Comparison of overall performance and acoustic signa- tures}

\subsection{Experimental setup}

Experimental global variables and acoustic spectra are used as a reference for the comparison between turbulence models. A turbocharger test rig installed in an anechoic chamber was employed to obtain the experimental measurements shown in this paper. A detailed description of the gas stand is given by Galindo et al. [24].

Figure 3 depicts a sketch of the turbocharger test rig, in which straight pipes placed at the inlet and outlet of the compressor are observed, along with piezoelectric pressure sensor

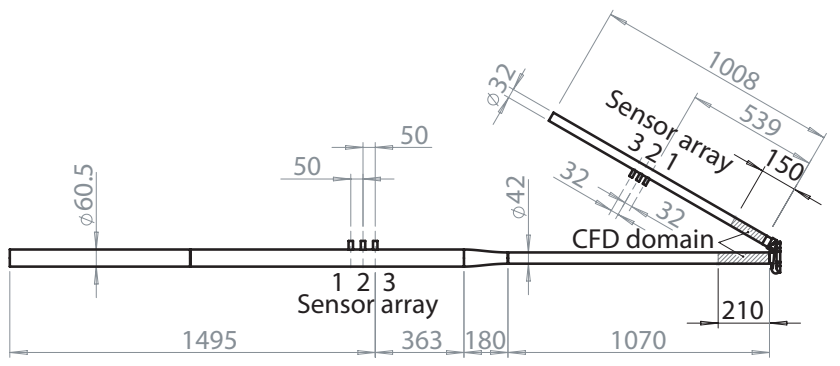

Figure 3: Compressor piping layout, highlighting the CFD domain and the sensor arrays. arrays. The use of these sensors instead of microphones in this work is justified by the low sensitivity of piezoelectric sensors to flow interaction and temperature effects, which are important in the compressor outlet. In addition, the threshold of these sensors at the frequency range of this study is low enough as to provide a signal-to-noise ratio of the measured signals between $20 \mathrm{~dB}$ and $30 \mathrm{~dB}$, depending on the operating point of the compressor.

A careful calibration of these sensors was essential for the correct application of the decomposition procedure, especially since one must ensure that any difference between pressure records corresponding to the different transducers is due to a difference in the actual pressure signal, and not to any eventual discrepancy between the behavior of the transducers themselves. To perform this calibration, the traditional method [25] based on a quasi-steady calibration by means of a deadweight tester with NPL and NIST traceability was carried out. Since the characteristic time of the measured signal is much longer than the response time of the transducer, a quasi-steady response of this device can be assumed when measuring pressure fluctuation in ducts. Under these assumptions, the relative error obtained from the calibration of each transducer is limited to $\pm 0.7 \%$. A Yokogawa digital oscilloscope was used to sample these pressure signals at $100 \mathrm{kHz}$ during 1 second at each operating condition.

Inlet and outlet linear arrays of three piezoelectric sensors each were designed in accordance with Piñero et al. [26]. In this way, the pressure trace can be decomposed into a forwardtraveling wave $p_{\text {forw }}(t)$ and a backward-traveling wave $p_{\text {back }}(t)$ by means of the beamforming-based signal analysis method developed by Piñero et al.

A full description of the experimental apparatus used to obtain the acoustical measurements was presented by Broatch et al. [17].

\subsection{Compressor performance variables}

Compressor global variables obtained with both turbulence models are first compared against experimental measurements. Standard definitions of total-to-total pressure ratio, specific work and isentropic efficiency are employed:

$$
\begin{aligned}
\Pi_{t, t} & =\frac{p_{\text {out }, 0}}{p_{\text {in }, 0}} \\
W_{u} & =\frac{\dot{W}}{\dot{m}}=\frac{\frac{2 \pi N(r p m)}{60} \tau}{\dot{m}}=c_{p}\left(T_{\text {out }, 0}-T_{\text {in }, 0}\right) \\
\eta_{s} & =\frac{\dot{W}_{s}}{\dot{W}}=\frac{T_{\text {in }, 0}\left(\Pi_{t, t}^{\frac{\gamma-1}{\gamma}}-1\right)}{T_{\text {out }, 0}-T_{\text {in }, 0}}
\end{aligned}
$$

Table 1 includes these overall variables for all operating conditions, along with relative difference against experimental measurements for numerical cases, defined as:

$$
\epsilon_{\text {exp }}(\%)=\frac{\left|\phi_{C F D}-\phi_{\text {exp }}\right|}{\phi_{\exp }} \cdot 100 .
$$


Table 1: Compressor global variables measured in the experimental test rig and predicted by the numerical model. In each box, the value is followed by the relative difference against experimental measurements.

\begin{tabular}{lcccc}
\hline Case & $\begin{array}{c}\dot{m} \\
{\left[g \cdot s^{-1}\right]}\end{array}$ & $\begin{array}{c}\Pi_{t, t}[-] \\
\left(\phi / \epsilon_{\text {exp }}\right)\end{array}$ & $\begin{array}{c}W_{u}\left[\mathrm{~kJ} \cdot \mathrm{kg}^{-1}\right] \\
\left(\phi / \epsilon_{\text {exp }}\right)\end{array}$ & $\begin{array}{c}\eta_{s}[\%] \\
\left(\phi / \epsilon_{\text {exp }}\right)\end{array}$ \\
\hline \multirow{3}{*}{ Exp } & 60 & $2.22 /-$ & $121 /-$ & $62.2 /-$ \\
& 77 & $2.24 /-$ & $112 /-$ & $67.9 /-$ \\
& 109 & $2.19 /-$ & $101 /-$ & $73.0 /-$ \\
\hline \multirow{3}{*}{ URANS } & 60 & $2.21 /-0.5$ & $122 / 0.7$ & $62.3 / 0.1$ \\
& 77 & $2.22 /-0.8$ & $111 /-0.6$ & $67.5 /-0.5$ \\
& 109 & $2.14 /-2.3$ & $99 /-2.1$ & $72.0 /-1.3$ \\
\hline \multirow{3}{*}{ DES } & 60 & $2.23 / 0.4$ & $122 / 0.6$ & $63.2 / 1.6$ \\
& 77 & $2.22 /-0.9$ & $111 /-0.8$ & $67.6 /-0.4$ \\
& 109 & $2.13 /-2.8$ & $99 /-2.6$ & $71.8 /-1.5$ \\
\hline
\end{tabular}

Numerical simulations predict compressor performance variables in agreement with experimental measurements, the error being no greater than $3 \%$. In contrast to what may be expected, operating conditions with higher mass flow rate present higher error, even though flow is expected to be more regular and thus easier to predict by means of CFD.

In terms of compressor global variables, URANS simulations show better agreement with experimental measurements than DES, particularly in pressure ratio evolution. However, differences between numerical and experimental global variables are driven by a combination of numerical errors and model uncertainty [27], and it should be noted that phenomena such as the eccentricity caused by shaft motion or heat transfer have not been modeled. Therefore, performance of turbulence models should not be assessed by prediction of overall variables alone.

\subsection{Compressor acoustic spectra}

The methodology developed by Broatch et al. [17] is used in order to obtain the compressor acoustic signature for the considered operating conditions. Pressure spectral densities (PSD) are estimated by means of Welch's overlapped segmented average [28]. Hamming windowing is used at blocks with $50 \%$ overlap. For each operating condition, the simulation is run until it achieves a steady state. Then, pressure signals are recorded at each time step (sampling rate of about $1 \mathrm{MHz}$ ) during no less than 120 additional impeller revolutions (47 ms). Finally, the signal is split into the number of blocks which provides the frequency resolution closest to $150 \mathrm{~Hz}$.

The acoustic analysis is performed dividing the spectra in two regions: plane wave range and high frequency range.

Plane wave range starts at the lowest frequency attainable and finishes with the onset of first asymmetric mode. The effect of standing waves on low frequency range spectra in numerical simulations is mitigated by the use of pressure decomposition [17]. As stated in Section 3.1, experimental signals are decomposed used the beamforming-based technique described by Piñero et al.[26], although it imposes a constraint on maximum frequency [17].
This constraint can be understood as the equivalent of the Nyquist frequency but for spatial instead of temporal sampling. It depends on the spacing between array sensors and the speed of sound, so it presents different values for inlet and outlet ducts. These frequencies are included in Table 2 along with other frequency values of interest:

Table 2: Summary of frequencies of interest.

\begin{tabular}{lc}
\hline Frequency & Value $[\mathrm{Hz}]$ \\
\hline CFD sampling & $10^{6}$ \\
Experimental sampling & $10^{5}$ \\
\hline Beamforming max. (inlet) & $3.4 \cdot 10^{3}$ \\
Beamforming max. (outlet) & $6.4 \cdot 10^{3}$ \\
\hline Asymmetric mode cut on (inlet) & $4.7 \cdot 10^{3}$ \\
Asymmetric mode cut on (outlet) & $7.4 \cdot 10^{3}$ \\
\hline Impeller rotation & $2.7 \cdot 10^{3}$ \\
Main blades passing & $16 \cdot 10^{3}$ \\
\hline
\end{tabular}

Pressure components in CFD are obtained by means of the following expressions:

$$
\begin{aligned}
& p_{\text {forw }}=p_{\text {ref }}\left[\frac{1}{2}\left(1+\left(\frac{p}{p_{\text {ref }}}\right)^{\frac{\gamma-1}{2 \gamma}}\left(1+\frac{\gamma-1}{2} \frac{u}{a}\right)\right)\right]^{\frac{2 \gamma}{\gamma-1}} \\
& p_{\text {back }}=p_{\text {ref }}\left[\frac{1}{2}\left(1+\left(\frac{p}{p_{\text {ref }}}\right)^{\frac{\gamma-1}{2 \gamma}}\left(1-\frac{\gamma-1}{2} \frac{u}{a}\right)\right)\right]^{\frac{2 \gamma}{\gamma-1}},
\end{aligned}
$$

which are inspired by the Method of Characteristics (MoC), as described by Torregrosa et al. [29]. Averaging of flow field variables at inlet and outlet cross-sections (see Fig. 1) is performed so as to obtain the pressure components.

High frequency range begins when the first asymmetric mode is cut on and is extended until $20 \mathrm{kHz}$. The onset frequency for this mode was estimated following Eriksson's method [30], being included in Table 2,

Broatch et al. [17] showed that point monitors located at wall ducts (see Fig. 1) should be used in this frequency range so as to capture higher order modes. Pressure decomposition $(\mathrm{Eq} 3 \mathrm{3}$ is again used to obtain the numerical spectra in order to reduce the impact of standing waves, whereas experimental pressure traces cannot be decomposed and thus a single probe of each array is used to obtain the raw PSD. Broatch et al. proved that decomposed numerical pressure spectra can be safely compared against raw experimental signals. Figures 477 show spectra obtained in the aforementioned way.

Experimental inlet PSD at low frequency range (Fig. 4) is almost flat for $109 \mathrm{~g} / \mathrm{s}$, showing two humps centered at 700 and $2700 \mathrm{~Hz}$. Both turbulence models accurately provide the same spectrum behavior at this operating condition, although DES slightly overpredicts the amplitude. Spectrum measured for 77 $\mathrm{g} / \mathrm{s}$ mass flow rate is flat, being greater in average than 109 g/s PSD. $77 \mathrm{~g} / \mathrm{s}$ spectra is almost identical for both turbulence approaches, and mimics experimental PSD overpredicting the 

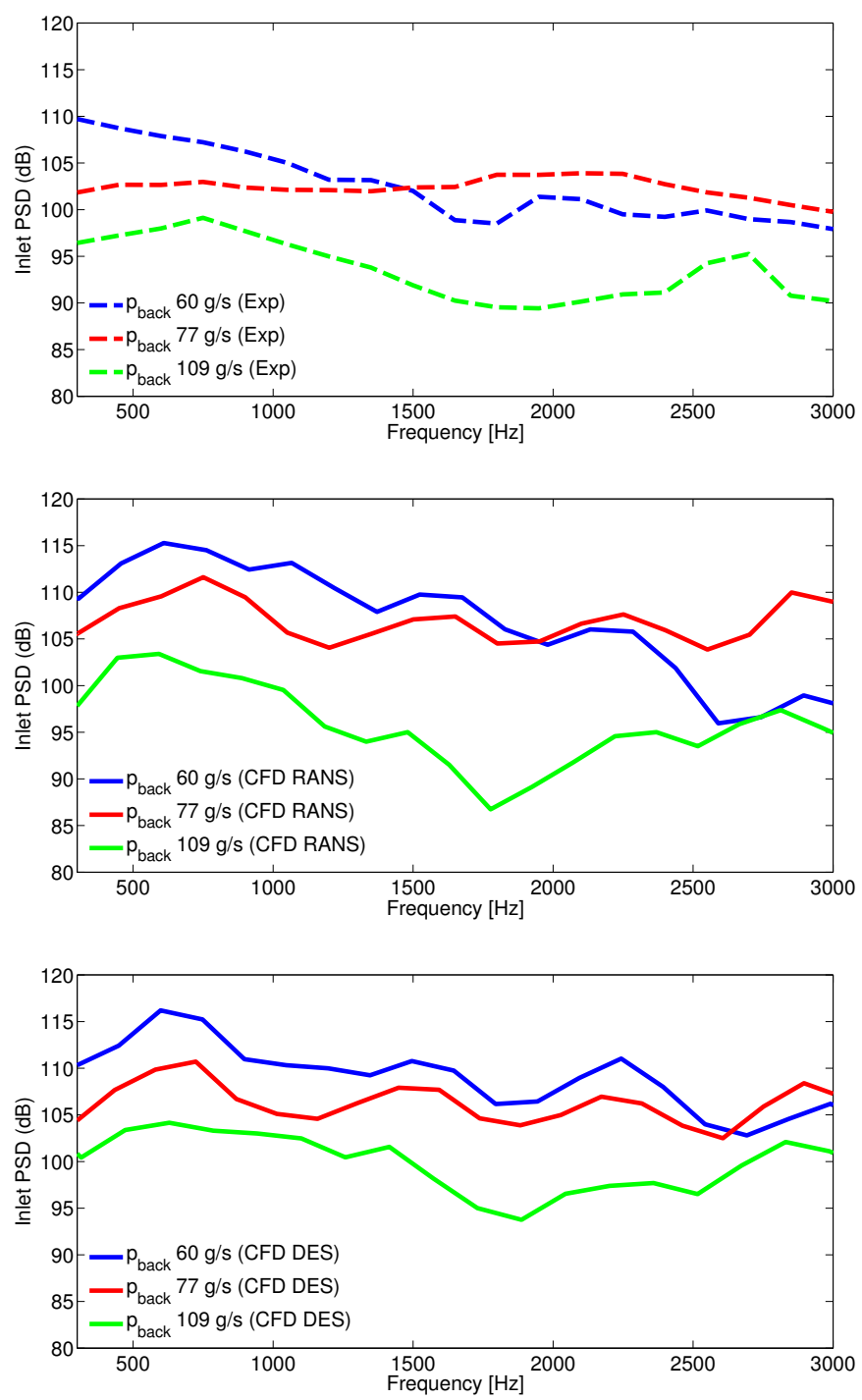

Figure 4: PSD of experimental (top) and numerical URANS (middle) and DES (bottom) pressure components at inlet duct, for the different operating conditions.

amplitude again. Finally, $60 \mathrm{~g} / \mathrm{s}$ spectrum decreases with frequency, intersecting $77 \mathrm{~g} / \mathrm{s}$ PSD at $1500 \mathrm{~Hz}$. For the point closest to surge $(60 \mathrm{~g} / \mathrm{s})$, numerical spectra does not depend on turbulence model until $1800 \mathrm{~Hz}$, where URANS overpredicts the negative slope of the PSD.

Outlet measured PSD at plane wave range (Fig. 57 presents a broadband elevation from 1.5 to $3 \mathrm{kHz}$ near BEP $(109 \mathrm{~g} / \mathrm{s})$, followed by a small hump centered at $4400 \mathrm{~Hz}$. URANS provides two broadband elevations in similar frequencies. Conversely, DES PSD for $109 \mathrm{~g} / \mathrm{s}$ is flat. Both turbulence approaches overpredict the amplitude at $109 \mathrm{~g} / \mathrm{s}$. Measured $77 \mathrm{~g} / \mathrm{s}$ spectrum includes a broadband elevation from 0.7 to $2.5 \mathrm{kHz}$, accurately reproduced by both turbulence models alike. Experimental PSD presents humps at 3500 and $4000 \mathrm{~Hz}$, which are captured by numerical simulations as a broadband noise elevation. Near surge, experimental spectrum decreases until 3500 $\mathrm{Hz}$, presenting a hump at $4000 \mathrm{~Hz}$ and then a constant value.
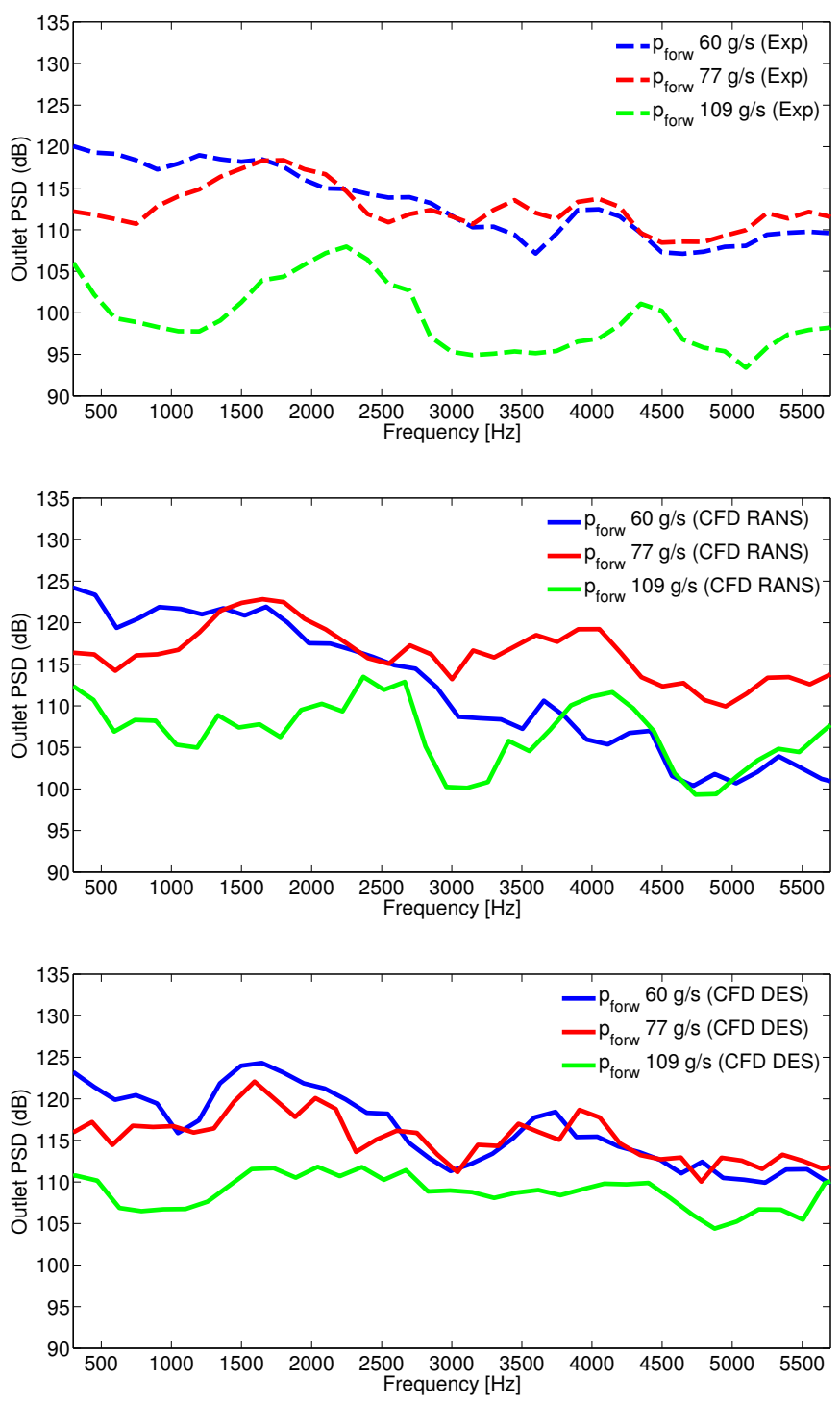

Figure 5: PSD of experimental (top) and numerical URANS (middle) and DES (bottom) pressure components at outlet duct, for the different operating conditions.

Conversely, URANS is unable to predict the change of PSD behavior at $3500 \mathrm{~Hz}$, thus providing a decreasing spectrum. DES does reflect this change of PSD evolution, although it includes a broadband elevation from 1 to $3 \mathrm{kHz}$ that is not present in the measured spectrum

Spectra depicted at Fig. 5 shows two broadband elevations in almost every case: one at a frequency from $50 \%$ to $90 \%$ of rotation speed and another from $120 \%$ to $170 \%$, which can be related to the whoosh noise phenomenon described in Section 1 . These ranges agree with the features observed at the works by Mendonça et al. [12] and Fontanesi et al. [13], despite the differences between sound speeds at outlet duct (caused by different pressure ratios). This fact suggests that whoosh noise is an aerodynamic sound not related to cavity resonances. Using the terminology of Mongeau et al. [31], whoosh noise is not a Helmholtz effect but a Strouhal one. Particularly, compressor speed plays a role in the onset of whoosh noise, as indicated by 

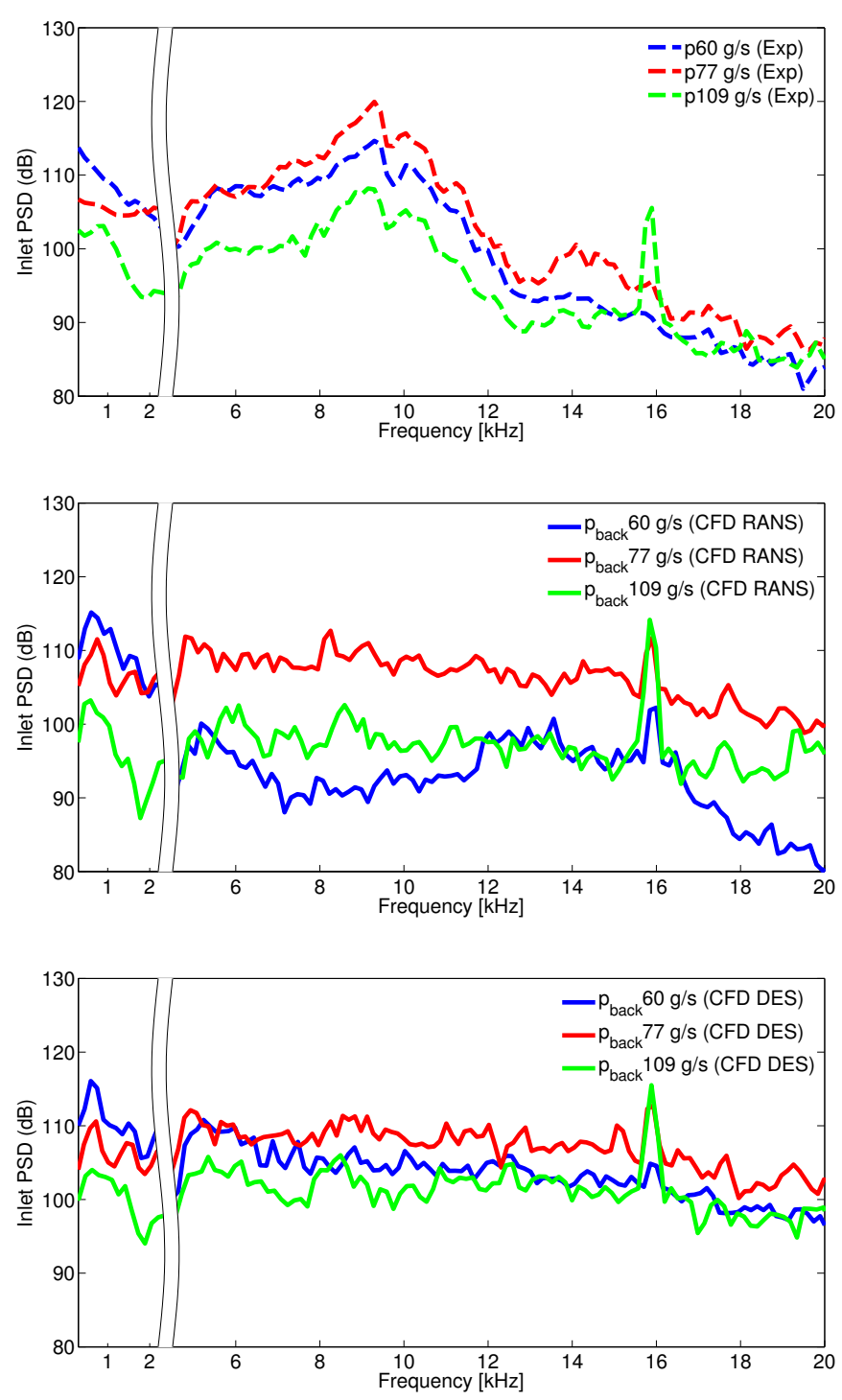

Figure 6: PSD of experimental pressure (top) and numerical URANS (middle) and DES (bottom) pressure components at inlet duct, for the different operating conditions.

Evans and Ward [3]. In fact, Després et al. [32] did not found any rotating stall at an operating point close to surge but at low compressor speed.

Experimental inlet spectra at high frequency range (Fig. 6) are alike for all operating conditions: they consist of a broadband noise elevation from 4.7 to $12.7 \mathrm{kHz}$ followed by a decreasing PSD. The differences are that the broadband elevation presents lower amplitude at $109 \mathrm{~g} / \mathrm{s}$ and main blade passing frequency (BPF) tone is more relevant near BEP $(109 \mathrm{~g} / \mathrm{s})$. Numerical simulations predict neither these broadband elevations at 4.7 to $12.7 \mathrm{kHz}$ nor a decreasing PSD at frequencies above $13 \mathrm{kHz}$. In fact, numerical spectra are almost flat regardless of the turbulence model. DES predicts an increase of average PSD as mass flow is reduced that is more in agreement with experimental measurements than URANS results. It should be noted that, as in the experimental spectra, BPF tone stands out in the inlet numerical PSD near BEP.
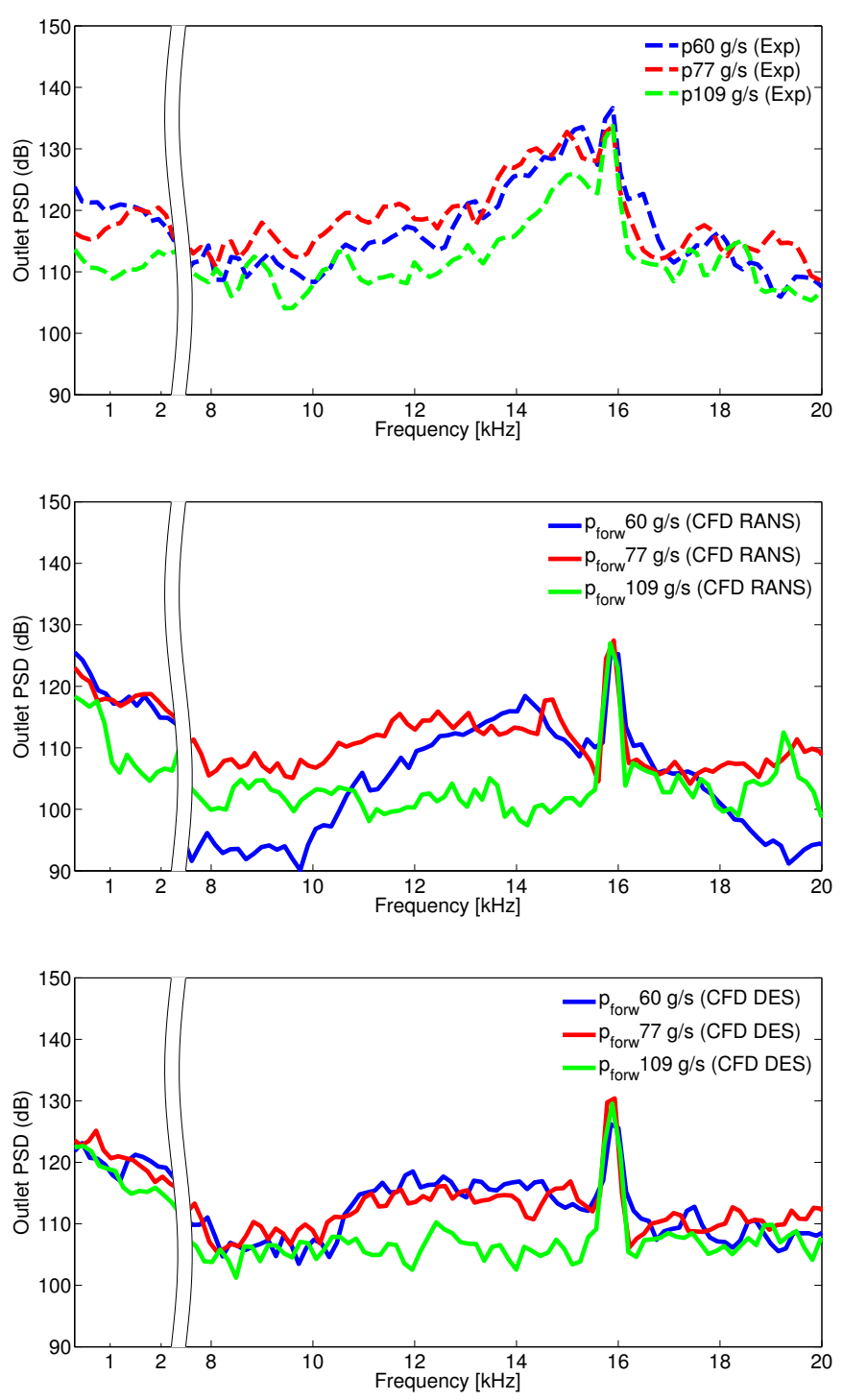

Figure 7: PSD of experimental pressure (top) and numerical URANS (middle) and DES (bottom) pressure components at outlet duct, for the different operating conditions.

Outlet duct spectra at high frequency range (Fig. 7) presents a similar description than inlet duct PSD (Fig. 6). In this case, BPF tones are evident for all operating conditions and experimental broadband elevation ranges from 13 to $16 \mathrm{kHz}$. Agreement between numerical simulations and measurements is much closer than with inlet spectra, even though the model is unable to provide the broadband elevation from 13 to $16 \mathrm{kHz}$. Again, the trend of average PSD against mass flow rate is better captured by DES.

Eventually, DES spectra provided in this section are quite similar to those predicted by URANS. Either DES does not significantly enhance the numerical prediction of pressure PSD for this particular application or the detached eddy-simulation is not properly capturing the large scales of the turbulence through the LES branch. The former would imply that the improved prediction of the turbulence of DES against URANS has little 
impact on the aerodynamic noise sources and the broadband sound generation due to turbulence does not significantly modify the acoustic signature.

On the other hand, even though the numerical configuration of DES was selected aiming at the highest affordable resolution, it may not be enough to cause a great improvement of turbulence prediction over URANS. Star-CCM+ [14] guidelines for DES were followed, therefore blending a $70 \%$ of a bounded central-differencing scheme with a $30 \%$ of a secondorder upwind scheme for the discretization of the convection term. Moreover, sensitivity studies of main setup parameters were conducted by Navarro [16] (see Section 2). Besides, Navarro showed that LES mode of DES is estimated to be active on the places in which large eddies are expected to appear, i.e., the region of the inlet duct just upstream the impeller, the inner part of rotor region (away from the walls) and the core of the volute. This does not guarantee that the LES branch presents the required accuracy, but some of the tools required for evaluating the resolution of Large Eddy Simulations (see the work of Davidson [33]) are not available when performing DES with Star-CCM+ [14].

On average, each time step of the conducted detached eddy simulations took $20 \%$ more computational time than the correspondent one using URANS. As indicated by Mannini [34], the expected increase of computational effort when moving from URANS to DES is not mainly due to the greater cost of solving a set of discretized equations corresponding to one cell, but to the demand of better spatial and temporal resolution. In this work, the same computational grid and time-step size were used for both turbulence modeling approaches as suggested by the sensitivity studies conducted by Navarro [16].

In any case, the following section will be focused on the analysis of DES results.

\section{Flow field investigation}

The flow field provided by the detached-eddy simulations is analyzed in order to find aeroacoustic phenomena that could be the source of the features observed in the PSD in Section 3.3 . To do this, blade-to-blade surfaces at $50 \%$ span are considered. Figure 8 depicts this postprocessing surface, that starts at the impeller's eye plane and finishes at the volute. In the following analysis, meridional velocity contours are shown at each operating condition. Meridional velocity is preferred over pressure contours because low frequency pressure waves are hidden under BPF tone, whose amplitude and frequency are higher. For a comparison of time-averaged flow field at these operating conditions, the reader may refer to the work of Navarro [16].

Figure 9 shows 4 snapshots of meridional velocity at $50 \%$ span surface for $109 \mathrm{~g} / \mathrm{s}$. These surfaces of revolution are unwrapped by projecting them on a normalized-meridional vs. circumferential plane [35]. The angle rotated by the impeller at each snapshot is indicated in the upper right corner of each frame. The sequence of pictures of Fig. 9 hence covers one main blade passing period. The volute tongue (VT) is marked with an arrow.

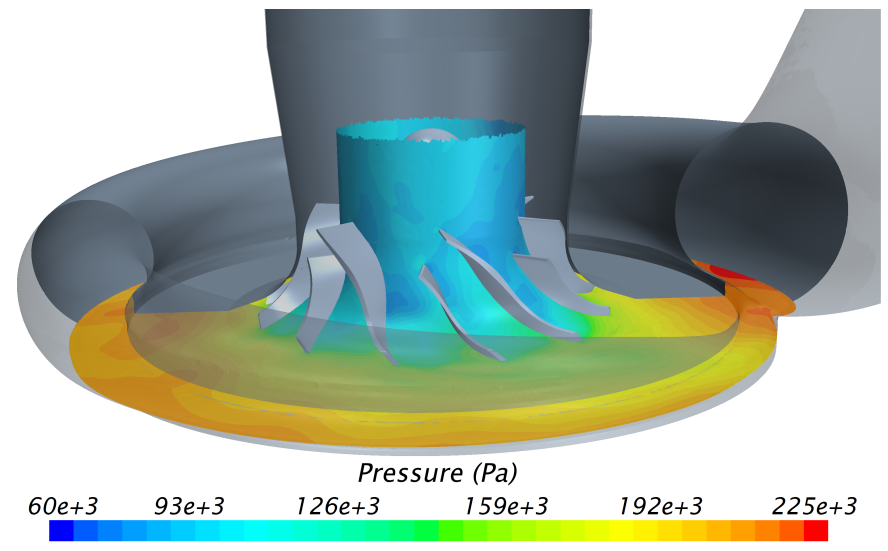

Figure 8: Blade-to-blade surface at 50\% span, showing contours of pressure for $60 \mathrm{~g} / \mathrm{s}$ operating conditions.

At these operating conditions, the flow upstream the blades is axisymmetric, becoming circumferentially periodic in the inducer and losing any symmetry as stalled regions appear at the exducer of some blades. Earliest flow dettachment occurs at splitter midchord distance. Stall is more intense at the suction side (SS) of the main blades, which indicates that splitter blades should be closer to main blade pressure side (PS) rather than being a midpitch distance. Després et al. [32] also noted that passages corresponding to main blade PS deliver more flow than channels which are delimited by the splitter blade PS for a midpitch location of the splitter blades. Moreover, Jeon [36] noted that, in a centrifugal fan, splitter blades located near main blade PS produce less overall SPL than the same impeller with splitter placed at a different pitchwise position.

The stalled regions, which in some cases present backflow (white contours in Fig. 9), result in the wake part of the classical jet-wake structure observed at the trailing edge. Meridional velocity displays almost a periodic circumferential profile again at the diffuser. Choi et al. [37] already noticed that a centrifugal pump presents negative radial velocity at blade SS even for operating conditions with higher mass flow than BEP.

Pulsating jets, identified as islands of warm colors in Fig. 9 appear at blades SS upstream the stalled regions. These jets are directed towards blades PS as they progress in the exducer due to flow slip, producing pressure waves which travel in the streamwise direction. The initial (top) and final (bottom) picture of those depicted in Fig. 9 show similarities. For instance, the jets at passage corresponding to the black splitter PS are in the same chordwise position at both snapshots, so the frequency of this phenomenon may be close to the main blade passing frequency.

Pressure is registered by a point probe located at trailing edge SS, which rotates in conjunction with the impeller as depicted by a black dot in Fig. 9 . Figure 10 shows PSD obtained using this probe for the different operating conditions. As will be seen later, the pressure field at the diffuser is strongly unaxisymmetric at $60 \mathrm{~g} / \mathrm{s}$ and $77 \mathrm{~g} / \mathrm{s}$, and thus a tone appears at the rotating order and harmonics. For $109 \mathrm{~g} / \mathrm{s}$, this feature also appears but with less amplitude, because the diffuser flow is more 

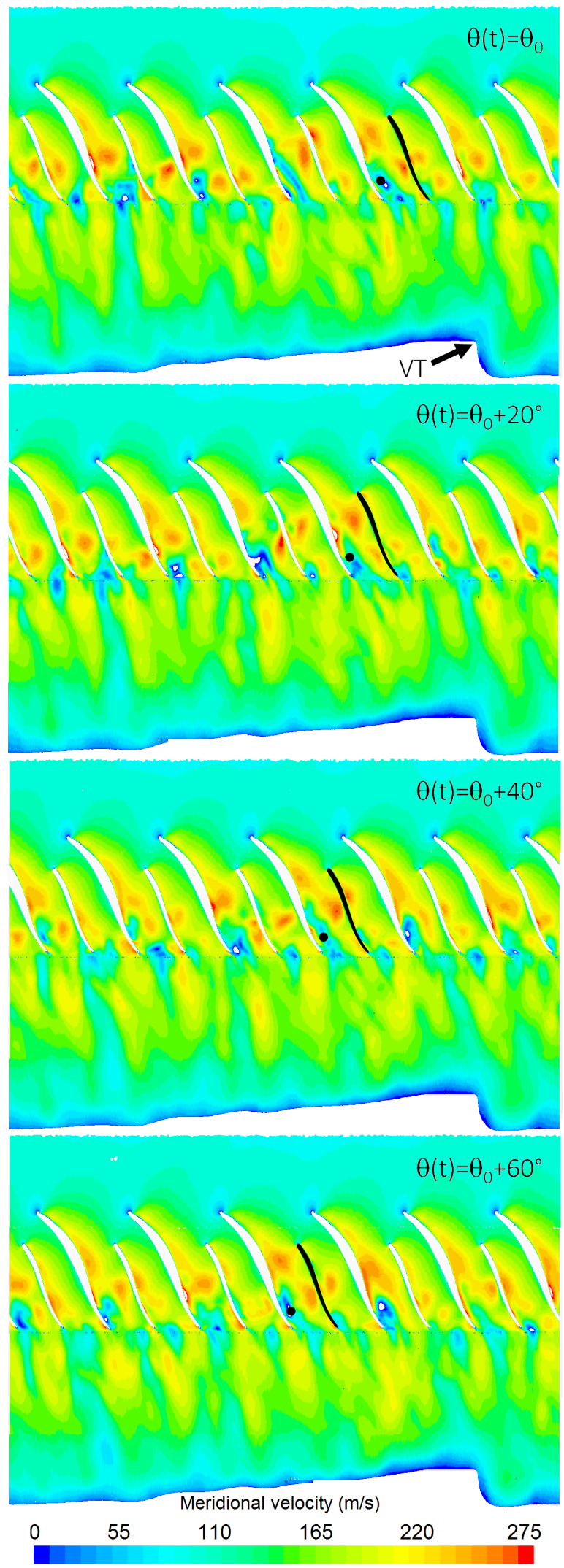

Figure 9: Snapshots of meridional velocity contours at 50\% span blade-to-blade surface, for $109 \mathrm{~g} / \mathrm{s}$ operating point. axisymmetric (see Fig. 9). In $109 \mathrm{~g} / \mathrm{s}$ trailing edge spectrum, a broadband centered at the BPF stands out, which therefore could be related with the phenomenon reflected in Fig. 9. In a similar way, Bousquet et al. [11] found that 6 vortices are formed and shed per revolution in their centrifugal compressor, thus being responsible of a observed tone at six times compressor rotational frequency. Besides, Pavesi et al. [38] attributed a tone corresponding to $66 \%$ of impeller rotation to a sequence of vortices in the wake region originated at blade midchord in a centrifugal pump with vaned diffuser.

Figure 11 corresponds to $77 \mathrm{~g} / \mathrm{s}$ operating conditions. Meridional velocity upstream main blades is almost periodic, except for one stall cell that rotates at about $30 \%$ of compressor speed. Bad incidence angle results in flow detachment at main blades leading edge, but passages do not stall until splitter blades leading edge chordwise location, upstream than in $109 \mathrm{~g} / \mathrm{s}$. The amount of spitchwise section stalled is increased regarding 109 $\mathrm{g} / \mathrm{s}$, and the asymmetry of flow going through main and secondary passages is not as remarkable as in $109 \mathrm{~g} / \mathrm{s}$. Flow at the diffuser is no longer axisymmetric: there is a zone of great radial velocity after the tongue followed by a region of stalled flow close to the volute.

The sequence of 4 snapshots included in Fig. 11 covers a timespan corresponding to one fourth of a full rotation. Pulsating jets at BPF are not found as in $109 \mathrm{~g} / \mathrm{s}$, which is supported by PSD depicted in Fig. 10 At $77 \mathrm{~g} / \mathrm{s}$, two low frequency phenomena appear. Upstream the impeller, a rotating stall cell has already been identified. At the diffuser and volute, stall cells also rotate at a subsynchronous speed. Regions of flow detached at the blades SS leave the trailing edge with the circumferential velocity imparted by the impeller. Conservation of angular velocity dictates that stalled cells reduce their tangential velocity as they progress in the radial direction through the diffuser. If these stalled cells are tracked, they move one twelfth of a full rotation in the timespan of Fig. 11, thus traveling at one third of the rotational speed. Since two stall regions can be identified, this phenomenon would result in an aeroacoustic source of about $1.8 \mathrm{kHz}$. If a greater timespan is considered, low velocity structures are convected through the outlet duct covering a range of frequencies slightly lower than compressor rotating speed. It is thus proposed that rotating stall is the

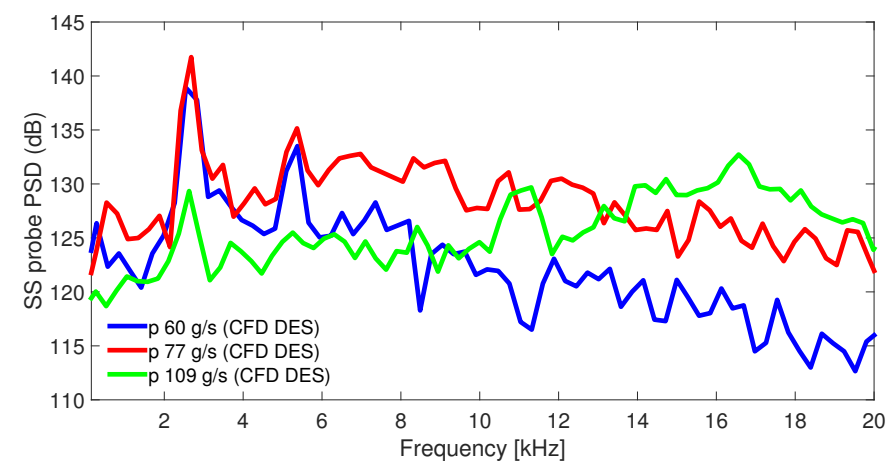

Figure 10: PSD of pressure trace calculated with DES at a probe located at the SS of the traling edge, for different operating conditions. 

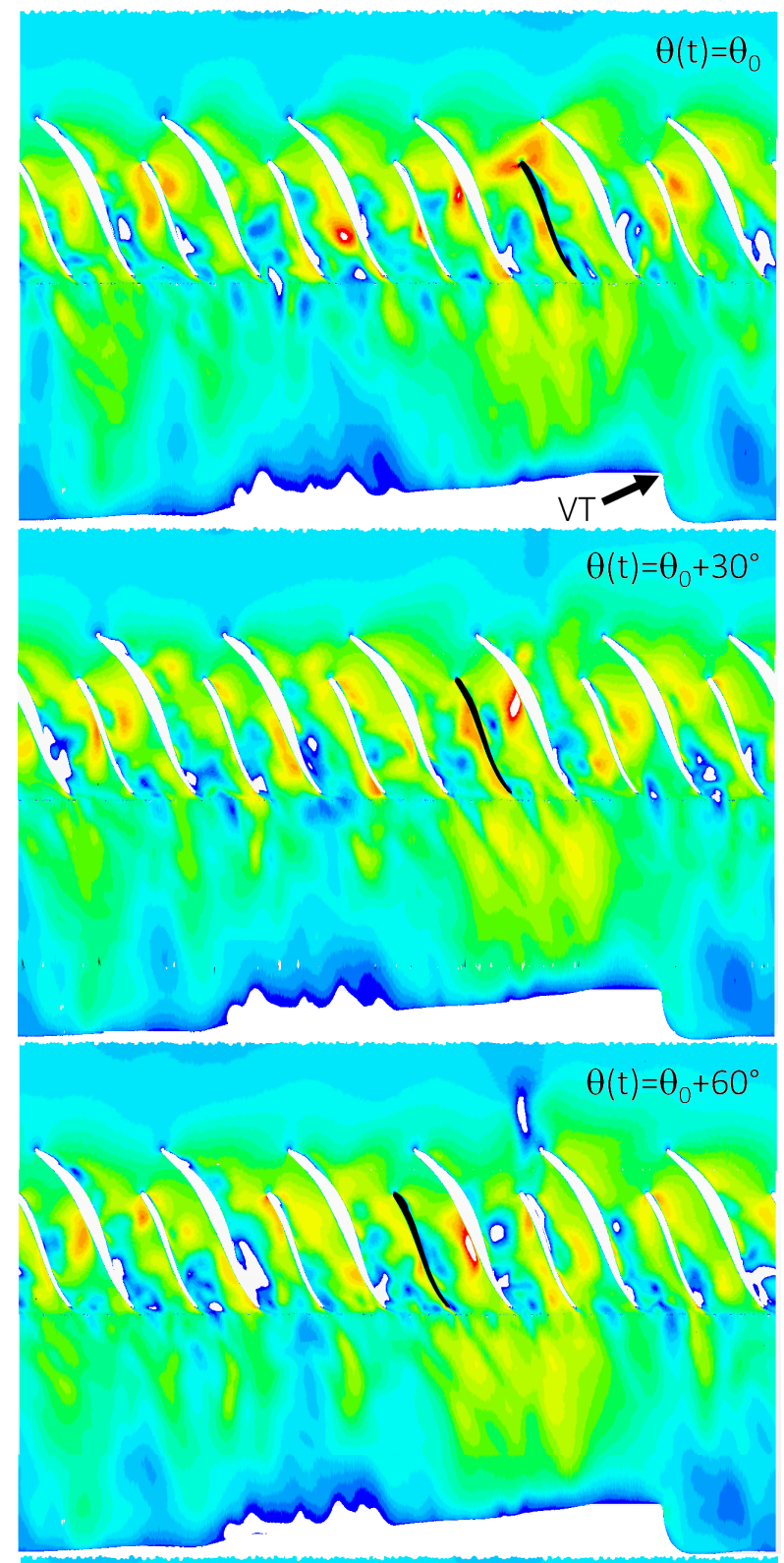

$$
\text { ( } \theta(\mathrm{t})=\theta_{0}+90^{\circ}
$$
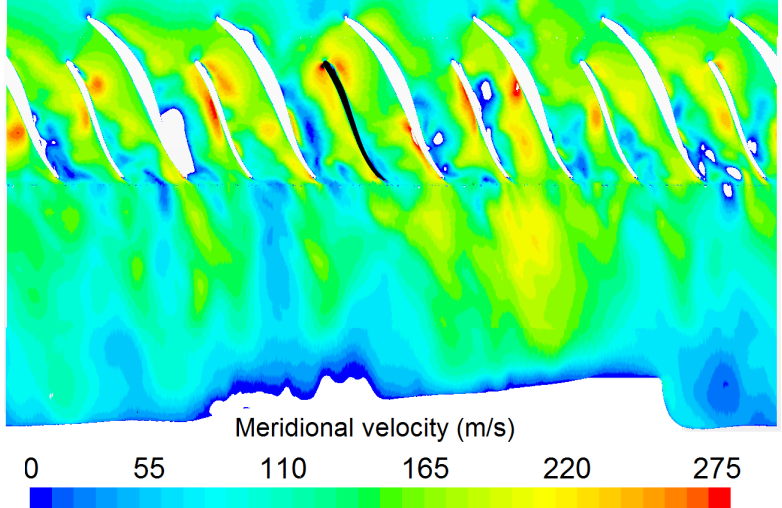

Figure 11: Snapshots of meridional velocity contours at $50 \%$ span blade-toblade surface, for $77 \mathrm{~g} / \mathrm{s}$ operating point.

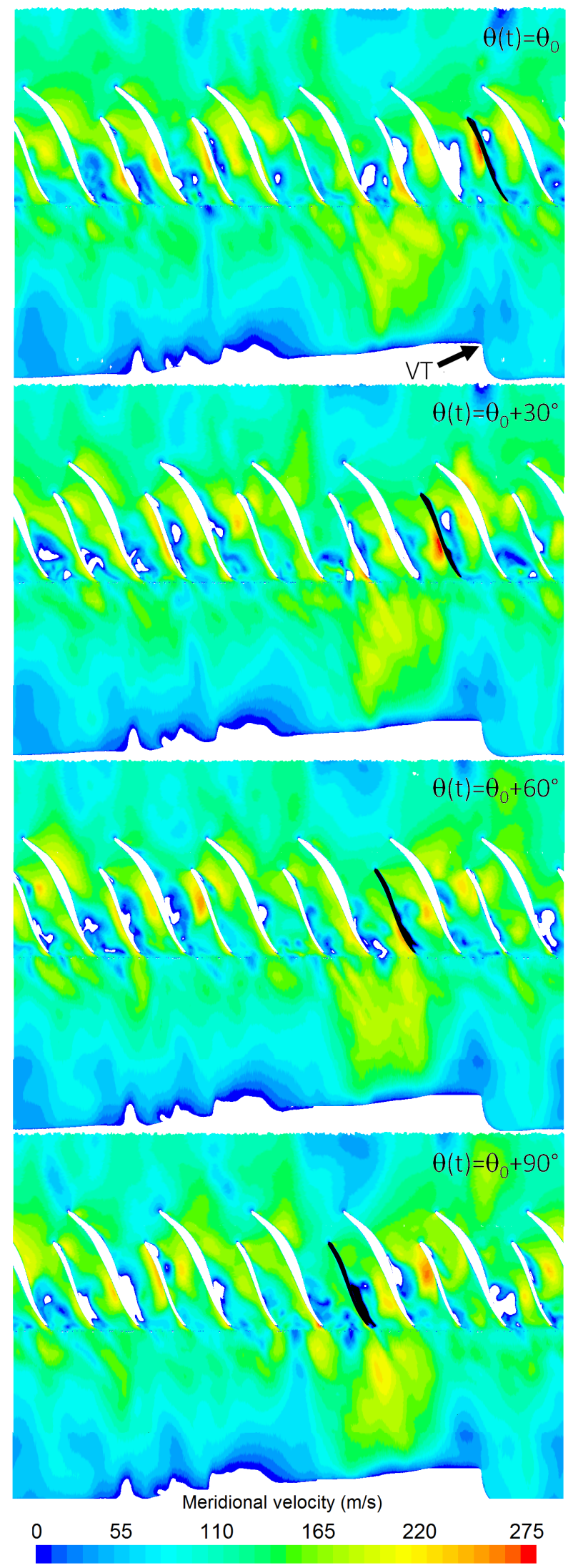

Figure 12: Snapshots of meridional velocity contours at $50 \%$ span blade-toblade surface, for $60 \mathrm{~g} / \mathrm{s}$ operating point. 
source of subsinchronous noise known as whoosh noise.

According to Choi et al. [37], jet-wake flow pattern of one passage disturbs adjacent passages, creating a rotating pattern than precesses around the impeller with a speed lower than shaft speed. In this way, even operating conditions not close to surge could present diffuser rotating stall and subsequent whoosh noise, as in the experimental spectrum for $109 \mathrm{~g} / \mathrm{s}$ (see top of Fig. 5).

Figure 12 is the counterpart of Fig. 11 but for $60 \mathrm{~g} / \mathrm{s}$, i.e., the same timespan is covered by the sequence of snapshots. Flow field at the passages, diffuser and volute looks alike $77 \mathrm{~g} / \mathrm{s}$. It agrees with the fact that outlet spectra depicted at Fig. 5 and Fig. 7 for $77 \mathrm{~g} / \mathrm{s}$ and $60 \mathrm{~g} / \mathrm{s}$ are very similar but for whoosh noise, which is more remarkable at $60 \mathrm{~g} / \mathrm{s}$ for DES. The main difference between these two operating points is found upstream the impeller. At $60 \mathrm{~g} / \mathrm{s}$, the reversed flow reaches several diameters upstream the impeller whereas for $77 \mathrm{~g} / \mathrm{s}$ the recirculation does not even reach the impeller's eye. Even though inducer rotating stall exists at both operating conditions, in the case closer to surge the rotating cells present a singular feature.

Figure 13 depicts a snapshot of the flow upstream the impeller at $60 \mathrm{~g} / \mathrm{s}$. Incoming streamlines, such as the ones colored by absolute value of helicity,

$$
H=\vec{v} \cdot(\nabla \wedge \vec{v})
$$

in Fig. 13, may suddenly find the recirculating flow, which presents high angular momentum (as discussed by Galindo et al. [15]). If that happens, incoming flow rolls up, thus increasing vorticity aligned with flow direction. This tornado-type vortex creates a region of low pressure.

For instance, a threshold of pressure below $85 \mathrm{kPa}$ is depicted in transparent blue in Fig. 13 , showing two low-pressure bubbles associated to the vortices. These structures rotate coherently with the inducer rotating stall, as marked by the arrows located over the cross-section which is colored by pressure. The tornadoes are not aligned with the impeller axis because the shear stress created by the backflows induce positive pre-rotation to the incoming flow. The case with $77 \mathrm{~g} / \mathrm{s}$ cannot present this phenomenon because the backflow does not go as far upstream.

Mendonça et al. [12] considered that inducer rotating stall was responsible for the numerical narrow band noise detected at a frequency of $70 \%$ of rotational speed. For the compressor and the rotational speed studied in this paper, maximum compression ratio point sets the onset of both inducer and diffuser rotating stall, along with whoosh noise. When mass flow is further reduced, inducer rotating stall is accompanied by a rotating low-pressure region created by tornado-type vortices. This phenomenon may increase the PSD below $1.5 \mathrm{kHz}$ seen in Figs. figures 45 .

\section{Conclusions and future work}

In this paper, URANS and detached eddy simulations of a turbocharger compressor at different operating conditions have been performed. Three points have been studied at nominal

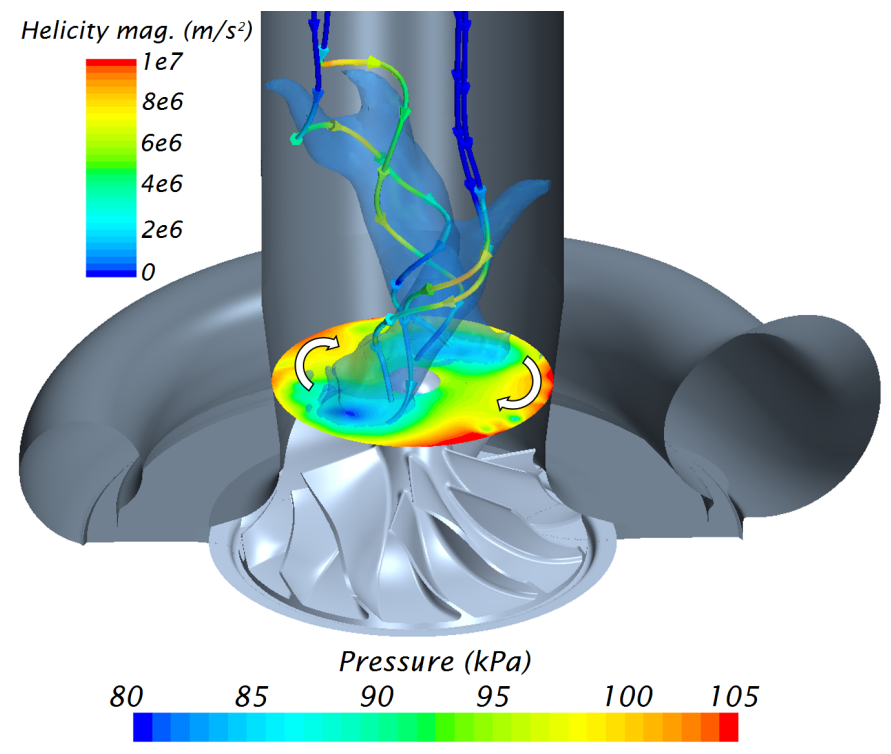

Figure 13: Snapshot of a pair of rotating tornado-type vortices at inlet duct for $60 \mathrm{~g} / \mathrm{s}$ mass flow rate.

speed: one close to the BEP, other at maximum pressure ratio and one close to surge. Pressure ratio, specific work and isentropic efficiency are predicted with relative differences compared to experiments below $3 \%$.

Pressure spectra have been investigated. Experimental PSD show that quietest point is the one with highest mass flow. The other two operating conditions present similar spectra, although point closest to surge is noisier below $1500 \mathrm{~Hz}$. Spectra predicted by simulations display the same tendencies, save for URANScalculated point at mass flow rate of $60 \mathrm{~g} / \mathrm{s}$. Whoosh noise is found as a broadband elevation in the range of 1 to $2.5 \mathrm{kHz}$. The only experimental PSD feature that simulations cannot reproduce is a broadband noise that appears at the inlet spectra between 4.7 and $12.7 \mathrm{kHz}$. DES did not provide a significant enhancement of the prediction of pressure spectra over URANS, even though it is a more advanced approach to model turbulence and takes $20 \%$ more computational time.

Numerical flow field predicted by DES at $109 \mathrm{~g} / \mathrm{s}$ depicts flow detachment at blades SS. The jet-wake pattern is found to be pulsating at a frequency slightly lower than main BPF. In any case, the flow is quite axisymmetric at these conditions. The other two points present a pattern similar between them and quite different from the one seen at $109 \mathrm{~g} / \mathrm{s}$. At the inducer, stall cells are rotating below compressor speed. Moreover, a tornado-type vortex causing a low-pressure bubble is also rotating at the inducer at $60 \mathrm{~g} / \mathrm{s}$. Flow detachment at blades SS is more pronounced than at $109 \mathrm{~g} / \mathrm{s}$. Circumferential profile of radial velocity at the diffuser is no longer axisymmetric, being dominated by a region with high speed near the volute tongue. Rotating instabilities are convected to the outlet duct at a frequency in the range of woosh noise. Therefore, it is the proposed fluid mechanism for this acoustic phenomenon.

Simulations at other operating conditions should be performed in order to complete the portrait of compressor acoustic signature. At least, points with same relative surge margin but 
different compressor speeds should be calculated to investigate if the aeroacoustic phenomena observed in this paper appears at different speeds. Isospeed points in the choke side could also be studied to shed some light on compressor flow-induced acoustics at high mass flow conditions.

\section{Acknowledgements}

This work has been partially supported by the Spanish Ministerio de Economía y Competitividad through grant No. TRA201236954. The equipment used in this work has been partially supported by FEDER project funds "Dotación de infraestructuras científico técnicas para el Centro Integral de Mejora Energética y Medioambiental de Sistemas de Transporte (CiMeT), (FEDER-ICTS-2012-06)", framed in the operational program of unique scientific and technical infrastructure of the Spanish Ministerio de Economa y Competitividad. Part of the computational resources used in this work have been provided by $\mathrm{Su}-$ percomputing Center of Universitat Politècnica de València and are thus gratefully acknowledged.

\section{List of Symbols}

$\begin{array}{lll}a & \text { speed of sound } & \mathrm{m} \cdot \mathrm{s}^{-1} \\ c_{p} & \text { specific heat capacity at constant pressure } & \mathrm{J} \cdot \mathrm{kg}^{-1} \cdot \mathrm{K}^{-1} \\ H & \text { helicity } & \mathrm{m} \cdot \mathrm{s}^{-2} \\ \dot{m} & \text { mass flow rate } & \mathrm{kg} \cdot \mathrm{s}^{-1} \\ N & \text { compressor rotational speed } & \mathrm{rpm} \\ p & \text { pressure } & \mathrm{Pa} \\ t & \text { time } & \mathrm{s} \\ T & \text { temperature } & \mathrm{K} \\ u & \text { axial velocity } & \mathrm{m} \cdot \mathrm{s}^{-1} \\ \vec{v} & \text { velocity } & \mathrm{m} \cdot \mathrm{s}^{-1} \\ \dot{W} & \text { compressor absorbed power } & \mathrm{kg} \cdot \mathrm{m}^{2} \cdot \mathrm{s}^{-3} \\ W_{u} & \text { compressor specific work } & \mathrm{m} \cdot \mathrm{s}^{-2} \\ \eta & \text { efficiency } & \% \\ \epsilon & \text { relative difference } & \% \\ \gamma & \text { ratio of specific heats } & - \\ \phi & \text { generic variable } & \\ \Pi_{t, t} & \text { total-to-total pressure ratio } & \mathrm{kg} \cdot \mathrm{m}^{2} \cdot \mathrm{s}^{-2} \\ \tau & \text { compressor torque } & \end{array}$

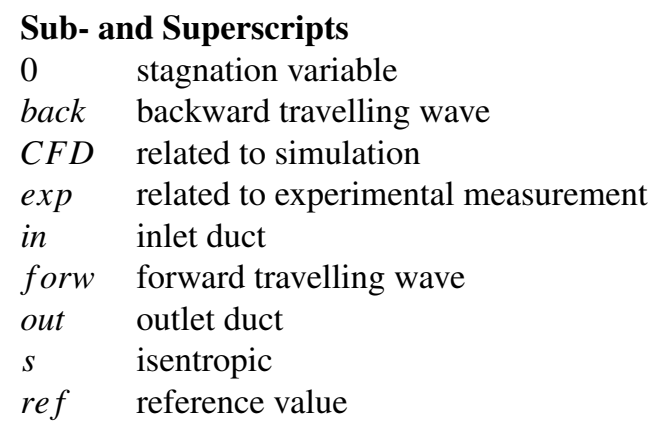

\section{References}

[1] M. Braun, S. Walsh, J. Horner, R. Chuter, Noise source characteristics in the ISO 362 vehicle pass-by noise test: Literature review, Applied Acous-

$\begin{array}{ll}\text { List of abbreviations } \\ \text { BEP } & \text { best efficiency point } \\ \text { BPF } & \text { blade passing frequency } \\ \text { CAD } & \text { computer-aided design } \\ \text { CBV } & \text { compressor by-pass valve } \\ \text { CFD } & \text { computational fluid dynamics } \\ \text { DDES } & \text { delayed DES } \\ \text { DES } & \text { detached eddy simulation } \\ \text { IDDES } & \text { improved DDES } \\ \text { LES } & \text { large eddy simulation } \\ \text { MoC } & \text { Method of Characteristics } \\ \text { NIST } & \text { National Institute of Standards and Technology (US) } \\ \text { NPL } & \text { National Physical Laboratory (UK) } \\ \text { NVH } & \text { noise, vibration, and harshness } \\ \text { PS } & \text { (blade) pressure side } \\ \text { PSD } & \text { power spectral density } \\ \text { RANS } & \text { Reynolds-averaged Navier-Stokes } \\ \text { SPL } & \text { sound pressure level } \\ \text { SS } & \text { (blade) suction side } \\ \text { VT } & \text { volute tongue } \\ \text { WMLES } & \text { wall-modeled LES } \\ & \end{array}$

tics 74 (11) (2013) 1241-1265. doi:10.1016/j. apacoust.2013.04. 005

[2] H. Stoffels, M. Schroeer, NVH Aspects of a Downsized Turbocharged Gasoline Powertrain with Direct Injection, SAE Technical Paper 200301-1664. doi:10.4271/2003-01-1664

[3] D. Evans, A. Ward, Minimizing Turbocharger Whoosh Noise for Diesel Powertrains, SAE Technical Paper 2005-01-2485. doi:10.4271/ 2005-01-2485

[4] C. Teng, S. Homco, Investigation of Compressor Whoosh Noise in Automotive Turbochargers, SAE Int. J. of Passeng. Cars-Mech. Syst. 2 (1) (2009) 1345-1351. doi:10.4271/2009-01-2053

[5] C. Sevginer, M. Arslan, N. Sonmez, S. Yilmaz, Investigation of turbocharger related whoosh and air blow noise in a diesel powertrain, in: Proceedings of the $36^{\text {th }}$ International Congress and Exposition on Noise Control Engineering 2007, 2007, pp. 476-485.

[6] K.-K. Ha, T.-B. Jeong, S.-H. Kang, H.-J. Kim, K.-M. Won, C.-Y. Park, W.-Y. Jung, K.-S. Cho, Experimental investigation on aero-acoustic characteristics of a centrifugal compressor for the fuel-cell vehicle, Journal of Mechanical Science and Technology 27 (11) (2013) 3287-3297. doi:10.1007/s12206-013-0851-y

[7] L. Mongeau, D. Thompson, D. Mclaughlin, A method for characterizing aerodynamic sound sources in turbomachines, Journal of Sound and Vibration 181 (3) (1995) 369-389. doi:10.1006/jsvi.1995.0146

[8] T. Raitor, W. Neise, Sound generation in centrifugal compressors, Journal of Sound and Vibration 314 (2008) 738-756. doi:10.1016/j.jsv. 2008.01 .034

[9] G. Liśkiewicz, L. Horodko, M. Stickland, W. Kryłłowicz, Identification of phenomena preceding blower surge by means of pressure spectral maps, Experimental Thermal and Fluid Science 54 (2014) 267-278. doi:10. 1016/j.expthermflusci.2014.01.002

[10] V. Jyothishkumar, M. Mihaescu, B. Semlitsch, L. Fuchs, Numerical flow analysis in centrifugal compressor near surge condition, in: Fluid Dynamics and Co-located Conferences, American Institute of Aeronautics and Astronautics, 2013, p. 13. doi:10.2514/6.2013-2730

[11] Y. Bousquet, X. Carbonneau, G. Dufour, N. Binder, I. Trebinjac, Analysis of the Unsteady Flow Field in a Centrifugal Compressor from Peak Efficiency to Near Stall with Full-Annulus Simulations, International Journal of Rotating Machinery 2014 (2014) 11. doi:10.1155/2014/729629

[12] F. Mendonça, O. Baris, G. Capon, Simulation of Radial Compressor Aeroacoustics using CFD, in: Proceedings of ASME Turbo Expo 2012, no. GT2012-70028, ASME, 2012, pp. 1823-1832. doi:10.1115/ GT2012-70028

[13] S. Fontanesi, S. Paltrinieri, G. Cantore, Cfd analysis of the acoustic be- 
havior of a centrifugal compressor for high performance engine application, Energy Procedia 45 (0) (2014) 759-768, aTI 2013 - 68th Conference of the Italian Thermal Machines Engineering Association. doi: 10.1016/j.egypro.2014.01.081

[14] CD-adapco,STAR-CCM+ release version 8.04.007 Edition (June 2013). URL http://www.cd-adapco.com

[15] J. Galindo, A. Tiseira, R. Navarro, M. López, Influence of tip clearance on flow behavior and noise generation of centrifugal compressors in nearsurge conditions, International Journal of Heat and Fluid Flow 52 (2015) 129-139. doi:10.1016/j.ijheatfluidflow.2014.12.004

[16] R. Navarro, A numerical approach for predicting flow-induced acoustics at near-stall conditions in an automotive turbocharger compressor Ph.D. thesis, Universitat Politècnica de València (2014). URL http://hdl.handle.net/10251/44114

[17] A. Broatch, J. Galindo, R. Navarro, J. García-Tíscar, Methodology for experimental validation of a CFD model for predicting noise generation in centrifugal compressors, International Journal of Heat and Fluid Flow 50 (2014) 134-144. doi:10.1016/j.ijheatfluidflow.2014.06.006

18] J. R. Serrano, P. Olmeda, F. Arnau, M. Reyes-Belmonte, A. Lefebvre, Importance of Heat Transfer Phenomena in Small Turbochargers for Passenger Car Applications, SAE International Journal of Engines 6 (2) (2013) 716-728. doi:10.4271/2013-01-0576

[19] F. R. Menter, Two-equation eddy-viscosity turbulence models for engineering applications, AIAA journal 32 (8) (1994) 1598-1605.

[20] F. R. Menter, R. Langtry, T. Hansen, CFD simulation of turbomachinery flows-verification, validation and modeling, in: European Congress on Computational Methods in Applied Sciences and Engineering, ECCOMAS, 2004.

[21] P. E. Smirnov, T. Hansen, F. R. Menter, Numerical Simulation of Turbulent Flows in Centrifugal Compressor Stages With Different Radial Gaps, in: Proceedings of GT2007, no. GT2007-27376, ASME, 2007. doi:10.1115/GT2007-27376

[22] Detached-eddy simulations past a circular cylinder, Flow, Turbulence and Combustion 63 (1-4) (2000) 293-313.

[23] M. L. Shur, P. R. Spalart, M. K. Strelets, A. K. Travin, A hybrid RANSLES approach with delayed-DES and wall-modelled LES capabilities, International Journal of Heat and Fluid Flow 29 (6) (2008) 1638-1649. doi:10.1016/j.ijheatfluidflow.2008.07.001

[24] J. Galindo, J. Serrano, C. Guardiola, C. Cervelló, Surge limit definition in a specific test bench for the characterization of automotive turbochargers, Experimental Thermal and Fluid Science 30 (5) (2006) 449-462. doi : 10.1016/j.expthermflusci.2005.06.002

[25] J. Tichỳ, G. H. Gautschi, Piezoelektrische Meßtechnik: physikalische Grundlagen, Kraft-, Druck-u. Beschleunigungsaufnehmer, Verstärker, Springer, 1980, ISBN: 978-3-642-52202-4.

[26] G. Piñero, L. Vergara, J. Desantes, A. Broatch, Estimation of velocity fluctuation in internal combustion engine exhaust systems through beamforming techniques, Measurement Science \& Technology 11 (11) (2000) 1585-1595. doi:10.1088/0957-0233/11/11/307

[27] H. K. Versteeg, W. Malalasekera, An introduction to computational fluid dynamics: the finite volume method, Prentice Hall, 2007.

[28] P. Welch, The use of fast fourier transform for the estimation of power spectra: a method based on time averaging over short, modified periodograms, Audio and Electroacoustics, IEEE Transactions on 15 (2) (1967) 70-73.

[29] A. J. Torregrosa, P. Fajardo, A. Gil, R. Navarro, Development of a nonreflecting boundary condition for application in 3D computational fluid dynamic codes, Engineering Applications of Computational Fluid Mechanics 6 (3) (2012) 447-460

[30] L. J. Eriksson, Higher order mode effects in circular ducts and expansion chambers, The Journal of the Acoustical Society of America 68 (1980) 545. doi:10.1121/1.384768

[31] L. Mongeau, D. Thompson, D. McLaughlin, Sound generation by rotating stall in centrifugal turbomachines, Journal of Sound and Vibration 163 (1) (1993) 1-30. doi:10.1006/jsvi.1993.1145

[32] G. Després, G. N. Boum, F. Leboeuf, D. Chalet, P. Chesse, A. Lefebvre, Simulation of near surge instabilities onset in a turbocharger compressor, Proceedings of the Institution of Mechanical Engineers, Part A: Journal of Power and Energy 227 (6) (2013) 665-673. doi:10.1177/ 0957650913495537

[33] L. Davidson, Large Eddy Simulations: How to evaluate resolution, In- ternational Journal of Heat and Fluid Flow 30 (5) (2009) 1016-1025. doi:10.1016/j.ijheatfluidflow.2009.06.006

[34] C. Mannini, Applicability of URANS and DES Simulations of Flow Past Rectangular Cylinders and Bridge Sections, Computation 3 (3) (2015) 479-508. doi:10.3390/computation3030479

[35] M. Drela, H. Youngren, A User's Guide to MISES 2.63, MIT Aerospace Computational Design Laboratory (2008).

[36] W.-H. Jeon, A numerical study on the acoustic characteristics of a centrifugal impeller with a splitter, GESTS International Transactions on Computer Science and Engineering 20 (1) (2005) 17-28.

[37] J.-S. Choi, D. K. McLaughlin, D. E. Thompson, Experiments on the unsteady flow field and noise generation in a centrifugal pump impeller, Journal of Sound and Vibration 263 (3) (2003) 493-514. doi:10.1016/ S0022-460X (02)01061-1

[38] G. Pavesi, G. Cavazzini, G. Ardizzon, Time-Frequency Characterization of Rotating Instabilities in a Centrifugal Pump with a Vaned Diffuser, International Journal of Rotating Machinery 2008 (2008) 10. doi:10. $1155 / 2008 / 202179$ 